\title{
Peptidyl-Prolyl Cis-Trans Isomerase FKBP1A
}

National Cancer Institute

\section{Source}

National Cancer Institute. Peptidyl-Prolyl Cis-Trans Isomerase FKBP1A. NCI Thesaurus.

Code $C 102485$.

Peptidyl-prolyl cis-trans isomerase FKBP1A (108 aa, $12 \mathrm{kDa})$ is encoded by the human FKBP1A gene. This protein is involved in both protein folding and the modulation of TGFbeta signaling. 